\title{
Microbial volatile organic compound emissions from Stachybotrys chartarum growing on gypsum wallboard and ceiling tile
}

\author{
Doris A Betancourt ${ }^{*}$, Ken Krebs, Scott A Moore and Shayna M Martin
}

\begin{abstract}
Background: Stachybotrys chartarum is a filamentous mold frequently identified among the mycobiota of water-damaged building materials. Growth of $\mathrm{S}$. chartarum on suitable substrates and under favorable environmental conditions leads to the production of secondary metabolites such as mycotoxins and microbial volatile organic compounds (MVOCs). The aim of this study was to characterize MVOC emission profiles of seven toxigenic strains of S. chartarum, isolated from water-damaged buildings, in order to identify unique MVOCs generated during growth on gypsum wallboard and ceiling tile coupons. Inoculated coupons were incubated and monitored for emissions and growth using a closed glass environmental growth chamber maintained at a constant room temperature. Gas samples were collected from the headspace for three to four weeks using Tenax TA tubes.

Results: Most of the MVOCs identified were alcohols, ketones, ethers and esters. The data showed that anisole (methoxybenzene) was emitted from all of the $S$. chartarum strains tested on both types of substrates. Maximum anisole concentration was detected after seven days of incubation.

Conclusions: MVOCs are suitable markers for fungal identification because they easily diffuse through weak barriers like wallpaper, and could be used for early detection of mold growth in hidden cavities. This study identifies the production of anisole by seven toxigenic strains of Stachybotrys chartarum within a period of one week of growth on gypsum wallboard and ceiling tiles. These data could provide useful information for the future construction of a robust MVOC library for the early detection of this mold.
\end{abstract}

Keywords: Stachybotrys chartarum, MVOC, Water-damaged building materials

\section{Background}

Stachybotrys chartarum is a filamentous mold usually identified among the mycobiota of wet-damaged, cellulosecontaining building material $[1,2]$. S. chartarum is usually referred to as "toxic mold"; toxicity has been associated with exposure to spores and production of mycotoxins [3-5]. In addition, S. chartarum and other indoor molds have been linked to damp building-related illnesses (DBRI) such as allergic reactions of the upper respiratory system (e.g. irritated eyes, nose and throat) [6]. Likewise, cases of idiopathic pulmonary hemosiderosis have been associated with $S$. chartarum indoor exposures [7,8]. Also,

\footnotetext{
*Correspondence: betancourt.doris@epa.gov

National Risk Management Research Laboratory, Air Pollution Prevention and Control Division, U.S. Environmental Protection Agency, E305-03, Durham, NC 27711, USA
}

S. chartarum may trigger immunologic, neurologic, and oncogenic disorders $[5,7,9]$.

Proper risk management decisions are necessary whenever $S$. chartarum is identified in mold-infested environments for the proper remediation of this mold and minimal exposure of occupational workers to its toxic effects $[10,11]$. At present, there are no standardized protocols to identify the need for mold-remediation for indoor built environments. Most of the published mold-remediation guidelines recommend visual inspection for fungal growth as part of the assessment for mold-remediation at damp or water-damaged settings. Usually by the time visible mold growth is observed, it implies that inaccessible areas within the building construction are already mold-contaminated $[11,12]$. The implementation of new technologies for close monitoring of secluded, damp spaces is necessary for the early detection of mold growth. Several studies suggested 
the use of microbial volatile organic compound (MVOC) profiles as a diagnostic tool to determine mold-related problems in homes and buildings [13-15]. MVOCs are volatile organic chemical emissions associated with mold metabolism and may be linked to some of the adverse respiratory conditions generated by S. chartarum [16-19]. Combinations of MVOC emissions generate characteristic odors; these are detected prior to visual mold growth in buildings where occupants complaint of poor indoor air quality $[20,21]$. MVOCs are suitable markers because they easily diffuse through weak barriers like wallpaper and small crevices $[12,15,20]$. Likewise, they could be used for early detection of mold growth in hidden cavities (i.e. air ducts) and infrequently-visited places such as attics, crawl spaces and basements $[12,22]$. Several studies suggest that MVOC emission patterns could be used for the identification and classification of closely related microorganisms $[23,24]$. Larsen and Frisvad [25] analyzed the MVOCs emissions pattern of 47 Penicillium taxa and showed and the MVOCs emission profiles were unique enough to classify Penicillium to the species level. In a previous study, our laboratory characterized MVOCs emitted by three toxigenic strains of $S$. chartarum when grown on Sabouraud Dextrose Agar (SDA) and gypsum wallboard [26]. In the present study, we included seven toxigenic strains of S. chartarum to identify unique MVOCs for this mold to help in the construction of a robust MVOC library. An MVOC fingerprinting profile will be very useful for the implementation of a method for the early detection and identification of mold contamination when other signs of mold growth are absent. These studies are expected to advance our basic understanding of the physiology of $S$. chartarum and provide useful knowledge for the early detection and control of this toxigenic mold.

\section{Methods}

Test organisms

Spores from seven toxigenic strains of Stachybotrys chartarum were used in this study. Strains ATCC 201210, ATCC 208877, ATCC 62762, ATCC 46994, and ATCC 34916 were obtained from the American Type Culture Collection (Manassas, VA); and strains RTI 3559 and RTI 5802 were isolated from water-damaged homes and were obtained from the RTI International Collection (Research Triangle Park, NC). Prior to testing, all S. chartarum strains were grown on SDA (Sabouraud Dextrose Agar) and characterized microscopically to verify purity of the culture. Spore suspensions were prepared as described in Crow et al. [27] with modifications for harvesting mold spores [28]. All S. chartarum strains were individually grown on SDA plates until spore production was observed. Approximately 4-5 plates were grown for each strain. Spores were harvested from plates with $3 \mathrm{ml}$ of $0.01 \mathrm{M}$ phosphate buffer containing $0.05 \%(\mathrm{v} / \mathrm{v})$ Tween 20
(Sigma Chemical, St Louis, MO, USA) at pH 7.0 (PBT $\mathrm{pH} 7.0$ ) by gently scraping the surface of the plate with a sterile bent glass rod. The spore suspensions of the 4-5 plates were combined and centrifuged at $12,000 \times \mathrm{g}$ for $5 \mathrm{~min}$. The supernatant was decanted leaving the spore pellet intact. The pellet was washed three times with $10 \mathrm{ml}$ of the $0.01 \mathrm{M} \mathrm{PBT}$ and stored at $4^{\circ} \mathrm{C}$ until needed. Total spore count of the stock spore suspension was determined by direct microscopic counting using a hemocytometer. The spore suspension was examined microscopically to verify purity of the spores (i.e., absence of hyphae). When needed, this stock of spore suspension was diluted to the desired concentration (spores/ml) using 0.01 M PBT.

\section{Test substrates}

Gypsum wallboard (W) and ceiling tiles (C) coupons were chosen as the cultivation substrate. The composition of the gypsum wallboard used was gypsum core $\left(\mathrm{CaSO}_{4}\right.$. $2 \mathrm{H}_{2} \mathrm{O}$ ) wrapped with paper. The composition of ceiling tile was wood fiber $(0-60 \%)$ and fibrous glass $(0-13 \%)$. Both materials were purchased at local vendors. $\mathrm{W}$ and $\mathrm{C}$ were cut into 3 in. $\times 1.5$ in. $(7.62 \mathrm{~cm} \times 3.81 \mathrm{~cm})$ coupons. All substrates were individually steam - sterilized by autoclaving prior to inoculation. To provide a suitable moist condition for the germination of $S$. chartarum spores, sterile coupons were individually placed on a sterile glass Petri dish and wetted with $4 \mathrm{ml}$ of sterile deionized $\mathrm{H}_{2} \mathrm{O}$. Previous studies showed that $S$. chartarum grows on prewetted building materials at relative humidity below $100 \%$ [29]. All $\mathrm{H}_{2} \mathrm{O}$ was allowed to absorb prior to inoculation. Coupons were inoculated by pipetting $100 \mu \mathrm{l}$ of spore suspension at the surface (usually with 10 spots of $10 \mu \mathrm{l}$ arranged in an X configuration). The coupons' preparation and the spiking procedure were performed in accordance with the ASTM guidelines D 6329-98 [30]. Spore concentration was $10^{5}-10^{6}$ per coupon.

\section{Sampling for MVOC emissions from static test chambers}

Figure 1 shows the experimental setup for the collection of MVOC emissions. Coupons inoculated with the predetermined spore load were contained in a static environmental growth chamber to quantitatively determine MVOC emissions. These chambers consisted of all-glass chambers, $4 \frac{3 / 4}{4}$ "W $\times 2 \frac{1}{2}$ " D $\times 4 \frac{1}{2}$ " $\mathrm{H}(12 \mathrm{~cm} \times 6.4 \mathrm{~cm} \times$ $11.5 \mathrm{~cm}$ ) (General Glassblowing Co., Inc., Richmond, CA) which were modified to include a face plate with two $1 / 4$ " Teflon bulkhead unions (with fritted glass disks); three glass culture plates (without lids), each with a test coupon; a wire mesh separator; 0 to $1 \mathrm{Lpm}$ Gilmont flowmeter (Cole Palmer, Vernon Hills, IL) and an individual small sample pump. The size of each chamber was approximately $820 \mathrm{ml}$.

The testing period was 21 to 28 days of incubation at room temperature. Each experimental run included one 

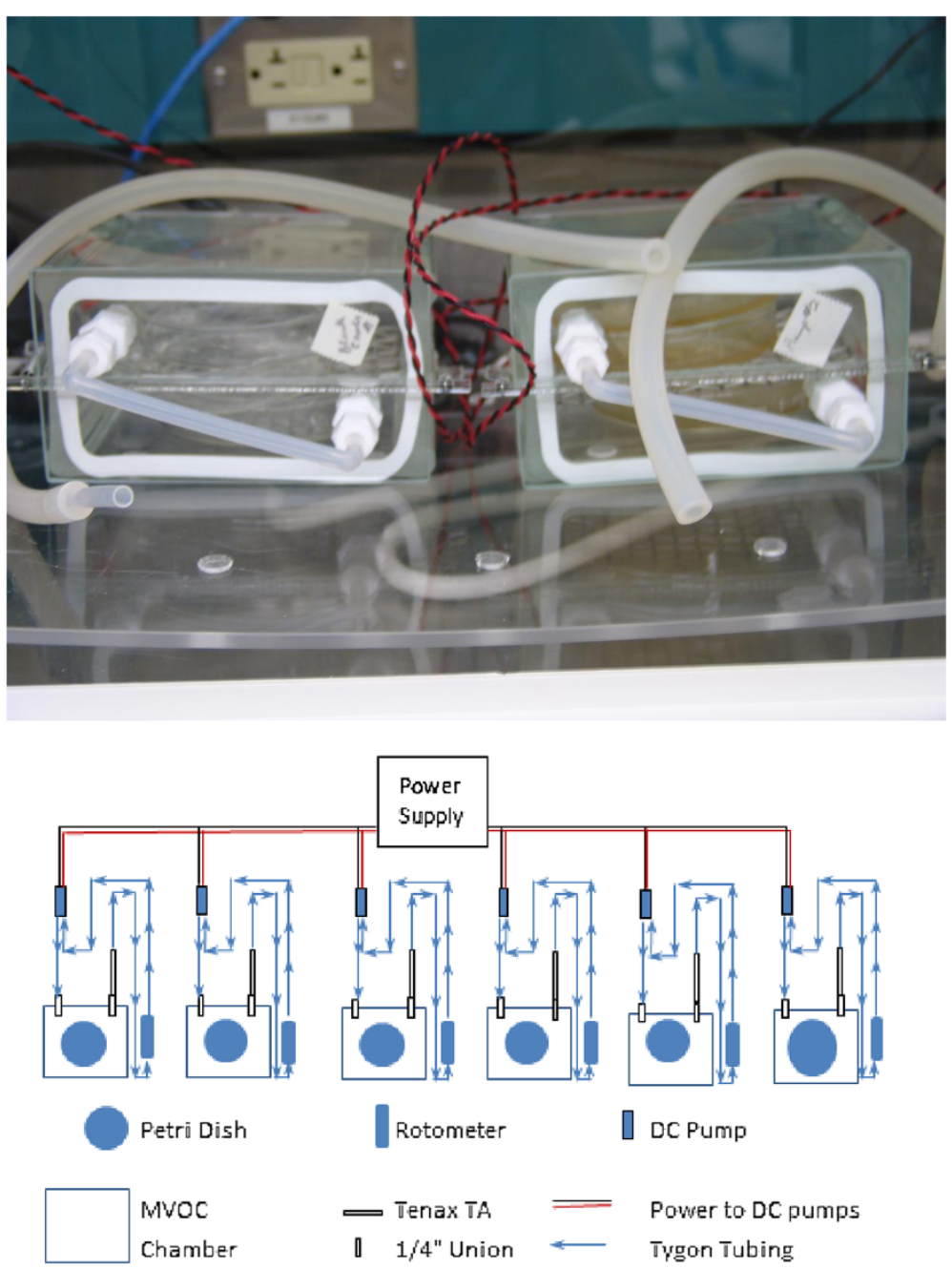

Figure 1 Experimental setup. The experimental setup allows for easily introducing the sorbent tubes into the sample loop without the need to open the growth chambers. A miniature pump draws the headspace from the chambers into the sorbent tube. The sample loop continues to a rotameter, where airflow is measured and is then transferred back into the growth chambers, thus providing a completely enclosed sample trajectory.

or two strains of $S$. chartarum (each tested individually) and only one type of coupon. Each strain was tested in duplicate chambers. Each run included a control chamber with no coupons and a negative control consisting of a chamber with sterile, un-inoculated coupons. The MVOC sampling media were Supelco Tenax TA tubes (Sigma-Aldrich, St. Louis, MO). On day one, three spore-loaded coupons, each placed in a glass Petri dish, were introduced into each of the chambers. The control and test chambers were closed and allowed to equilibrate overnight at room temperature prior to the initiation of the testing period. After the equilibration period, the air from the headspace was collected onto Tenax TA tubes for 90 minutes at a nominal airflow of 0.05 liter per minute. Weekly headspace samples were collected within a period of 21 to 28 days.
MVOC samples collected on Tenax TA tubes were temperature desorbed according to published procedures described in EPA Method TO -17 and analyzed using an Agilent 6890/5973 Gas Chromatography/ Mass Spectrometry (GC/MS) with Perkin Elmer Automated Thermal Desorber 400 system (PE ATD 400). For the instrument calibration, the relative response factor (RRF) method based on peak areas of extracted ion of target analytes relative to that of the internal standard was used. Gas phase $d_{8}$-toluene was used as the internal standard. The following MVOCs, identified in a previous study, were used to calibrate the instrument: isoamyl alcohol (3-methyl-1-butanol), styrene, 3octanone, anisole (methoxybenzene), cyclohexanol, and naphthalene, all purchased from Chem Service (West Chester, PA, USA); 4-methylanisole (1-methoxy-4-methylbenzene), 3-methylanisole (1-methoxy-3-methylbenzene), 
and 3,5-dimethoxytoluene purchased from Sigma-Aldrich (St. Louis, MO, USA) [26]. The calibration standards were prepared at five concentration levels ranging from approximately 4 to $400 \mathrm{ng} / \mu \mathrm{l}$ in $\mathrm{CH}_{3} \mathrm{OH}$. Two $\mu \mathrm{l}$ of standards were spiked on each Tenax TA tube for the calibration. The practical quantification limit (PQL) which is the lowest calibration concentration was $8 \mathrm{ng} /$ tube for each target analyte.

Target MVOC values in the samples are reported in micrograms per cubic meter $\left(\mu \mathrm{g} / \mathrm{m}^{3}\right)$. The MVOC concentration $(\mathrm{C})$ was determined using Equation 1.

$$
C=M / V
$$

Where: $\mathrm{M}$ is the mass of the MVOC measured on each Tenax sampling tube, ng; $\mathrm{V}$ is the air sample volume, liter; and $C$ is the concentration, $\mu \mathrm{g} / \mathrm{m}^{3}$.

Other fungal metabolites were identified with less certainty using a general mass spectral library available from the National Institute of Standards and Technology (NIST). VOC profiles were generated for each chamber. For each test period we had three types of VOC profiles: background VOCs; negative control VOCs; and positive controls VOCs. Background VOCs were those detected from the chambers without test coupons. Negative control VOCs were the emissions identified in chambers with test coupons without mold spores; most of the VOCs in these chambers were a combination of background and emissions from the wallboard (or ceiling tile) coupons. Positive control VOCs were those emitted from the coupons with mold spores; these emissions were a combination of MVOCs plus the previously mentioned VOCs. By comparing the three profiles, we identified the MVOCs emissions as $S$. chartarum grew either in W or C.

\section{Determination of mycotoxin and colony-forming unit (CFU)}

Coupons loaded with S. chartarum spores were placed inside sterile glass Petri dishes and incubated in static growth chambers during the same testing period as the MVOC chambers. To verify the toxigenicity of the $S$. chartarum strains, we used the Envirologix QuantiTox kit for trichothecenes (Envirologix Inc., Portland, ME). The manufacturer's protocol was used for mycotoxin extractions and assays. CFU analysis was done to monitor viability and growth of $S$. chartarum during the test period. The CFU analysis was done as described by Betancourt et al. [31].

\section{Results and discussion}

In this study, we followed the MVOCs emissions from seven toxigenic strains of $S$. chartarum as they grew on cellulose-based gypsum wallboard (W) and ceiling tile (C). These essential building materials, used in the construction of walls and ceilings, are known to support microbial growth and become mold-colonized in a short period of time in damp or water-damaged indoor environments. Under these conditions, Stachybotrys chartarum is frequently identified among the mycobiota $[1,2,32,33]$.

Additional file 1: Table S1 summarizes the MVOC emission profiles of $S$. chartarum growing on W and C. Most of the MVOCs identified were alcohols, ketones, hydrocarbons, ethers and esters. All these MVOCs have previously been reported as fungal metabolites [14,20,21,26,34-39]. The highlighted MVOCs were those emitted by four or more strains of $S$. chartarum on one or both of the substrates. These MVOCs were: anisole (methoxybenzene); 3-octanone; 3-methyl-3-buten1-ol; 2-butanol; 2-(1-cyclopent-1-enyl-1-methylethyl) cyclopentanone; and 3,4-dihydro-8-hydroxy-3-methyl(R)-1H-2-Benzopyran-1-one. Only the MVOCs emitted in both chambers (i.e., in duplicate) for the same mold strain were reported. Several studies showed that MVOC emissions' profiles are very diverse; i.e., they vary depending on the fungi, the types of substrates available, and the existent environmental conditions (i.e., moisture, temperature) $[14,40,41]$. In this study, we observed this variability among the different $S$. chartarum strains and even within the same $S$. chartarum strain growing on different substrates (Additional file 1: Table S1). However, some MVOC emissions were highly reproducible even among different $S$. chartarum strains. We measured the MVOC concentrations of the following: anisole (methoxybenzene), 3octanone, 3-methyl-1-butanol (isoamylalcohol), styrene, cyclohexanol, 4-methylanisole (1-methoxy-4-methylbenzene), 3-methylanisole (1-methoxy-3-methylbenzene), naphthalene, and 3,5-dimethoxytoluene based on the results of a previous study [26]. Only the concentrations of anisole and 3-octanone are reported; all the other MVOC tested were below detection limits (data not shown). Tables 1 and 2 summarize the concentrations of anisole (methoxybenzene), 3-octanone, mycotoxin and corresponding colony forming units (CFU) during different incubation times. Figures 2 and 3 represent the emissions pattern of both MVOCs on W and C, respectively. Our study showed that all seven strains (except ATCC 208877 which was not grown on C) emitted anisole on both wallboard and ceiling tile after 1 week of incubation and its concentration peaked within this timeframe. The concentration of anisole generated by the different strains was generally higher when grown on wallboard than on ceiling tiles (compare Figures 2 and 3 and note the difference in the scale of the Y-axis). Furthermore, the error bars were found to be larger for the gypsum wallboard (Figure 2) than those for ceiling tile (Figure 3); this is probably due to differences in the composition of the nutrient availability in the two building material as evident from the higher rate of anisole emission from the gypsum wallboard as compared to ceiling tile. 
Table 1 Growth, MVOC emissions and mycotoxin production by Stachybotrys chartarum growing on gypsum wallboard

\begin{tabular}{|c|c|c|c|c|c|c|}
\hline $\begin{array}{c}\text { Stachybotrys } \\
\text { chartarum strain }\end{array}$ & Substrate $^{a}$ & $\begin{array}{l}\text { Incubation } \\
\text { period } \\
\text { (Days) }\end{array}$ & $\begin{array}{c}\text { Anisole } \\
\text { concentration } \\
\left(\mu \mathrm{g} / \mathrm{m}^{3}\right) \\
\text { Mean } \pm \mathrm{SD}^{\mathrm{b}}(\mathrm{n})^{\mathrm{c}}\end{array}$ & $\begin{array}{c}\text { 3-octanone } \\
\text { concentration } \\
\left(\mu \mathrm{g} / \mathrm{m}^{3}\right) \\
\text { Mean } \pm \mathrm{SD}(\mathrm{n})\end{array}$ & $\begin{array}{c}\text { Mycotoxin } \\
\text { concentration } \\
\text { (ppb) }\end{array}$ & $\begin{array}{l}\text { CFU } \log _{10} \\
\text { Mean } \pm \text { SD }\end{array}$ \\
\hline \multirow[t]{3}{*}{ ATCC 201210} & W & Start & $0.25 \pm 0.05(2)$ & $3.18 \pm 0.88(2)$ & $N D^{d}$ & $6.38 \pm 6.44$ \\
\hline & & $7 d$ & $65.92 \pm 22.87(2)$ & $1.36(1)$ & ND & $9.34 \pm 8.99$ \\
\hline & & $14 \mathrm{~d}$ & $14.71 \pm 7.27(2)$ & $1.59 \pm 0.58(2)$ & ND & $9.96 \pm 9.09$ \\
\hline \multirow[t]{5}{*}{ ATCC 62762} & W & Start & $0.12 \pm 0.02(2)$ & $0.20 \pm 0.02(2)$ & 0.2 & $6.1 \pm 5.91$ \\
\hline & & $7 d$ & $50.1 \pm 5.35$ & $1.43 \pm 0.24(2)$ & $<0.2$ & $6.59 \pm 6.03$ \\
\hline & & $14 \mathrm{~d}$ & $12.26 \pm 0.78$ & $1.75 \pm 0.11(2)$ & 0.2 & $7.31 \pm 6.83$ \\
\hline & & $21 \mathrm{~d}$ & $5.10 \pm 0.18$ & $1.34 \pm 0.11(2)$ & 2.0 & $6.90 \pm 6.56$ \\
\hline & & $28 d$ & $2.52(1)$ & $0.46(1)$ & $>18$ & $8.25 \pm 7.45$ \\
\hline \multirow[t]{5}{*}{ ATCC 34916} & W & start & $0.34 \pm 0.12(2)$ & $B D L^{e}$ & $<0.2$ & TFTC \\
\hline & & $7 d$ & $57.85 \pm 5.03$ & $1.83 \pm 0.80(2)$ & $>18$ & $9.45 \pm 8.48$ \\
\hline & & $14 \mathrm{~d}$ & $13.10 \pm 0.21$ & $2.31 \pm 0.65(2)$ & $>18$ & $9.94 \pm 9.31$ \\
\hline & & $21 \mathrm{~d}$ & $6.57 \pm 0.08$ & $2.23 \pm 0.56(2)$ & $>18$ & $10.45 \pm 9.95$ \\
\hline & & $28 d$ & $3.75(1)$ & $0.54(1)$ & $>18$ & $9.9 \pm 9.19$ \\
\hline \multirow[t]{4}{*}{ ATCC 208877} & W & Start & $0.62 \pm 0.09$ & $1.44 \pm 0.19(2)$ & $<0.2$ & 5 \\
\hline & & $7 d$ & $105.19 \pm 37.96$ & $4.37 \pm 0.71$ & $0.2<x<2.0$ & $7.99 \pm 7.40$ \\
\hline & & $14 \mathrm{~d}$ & $36.58 \pm 10.44(2)$ & $2.52 \pm 0.45(2)$ & 18 & $9.55 \pm 8.9$ \\
\hline & & $21 \mathrm{~d}$ & $18.72(1)$ & $2.45(1)$ & $2.0<x<18$ & $9.49 \pm 9.06$ \\
\hline \multirow[t]{5}{*}{ ATCC 46994} & W & Start & $0.75 \pm 0.05$ & $0.28(1)$ & $<0.2$ & TFTC \\
\hline & & $7 d$ & $46.37 \pm 6.78(2)$ & $2.16 \pm 0.06(2)$ & 0.2 & $8.86 \pm 8.83$ \\
\hline & & $14 \mathrm{~d}$ & $11.60 \pm 2.31(2)$ & $4.16 \pm 0.79(2)$ & $0.2<x<2.0$ & $9.78 \pm 9.30$ \\
\hline & & $21 \mathrm{~d}$ & $6.25 \pm 0.76$ & $3.77 \pm 0.65(2)$ & $0.2<x<2.0$ & $10.10 \pm 9.52$ \\
\hline & & $28 d$ & $4.56(1)$ & $6.16(1)$ & $0.2<x<2.0$ & $10.47 \pm 9.32$ \\
\hline \multirow[t]{5}{*}{ RTI 3559} & W & Start & $0.15 \pm 0.03$ & $0.26 \pm 0.15$ & 0.2 & $6.22 \pm 5.61$ \\
\hline & & $7 d$ & $48.15 \pm 7.39$ & $0.94(1)$ & 18 & $8.96 \pm 9.07$ \\
\hline & & $14 \mathrm{~d}$ & $9.64(1)$ & $0.13(1)$ & 18 & $10.36 \pm 9.64$ \\
\hline & & $21 \mathrm{~d}$ & $4.89 \pm 0.64(2)$ & $0.71 \pm 0.04$ & 18 & $10.29 \pm 9.82$ \\
\hline & & $28 d$ & $3.16(1)$ & $0.94(1)$ & $>18$ & $9.27 \pm 8.36$ \\
\hline \multirow[t]{4}{*}{ RTI 5802} & W & Start & $0.58 \pm 0.11$ & $2.22 \pm 1.60(2)$ & $<0.2$ & $5.22 \pm 4.76$ \\
\hline & & $7 d$ & $61.74 \pm 12.72(3)$ & $1.71 \pm 0.23$ & 0.2 & $8.5 \pm 7.53$ \\
\hline & & $14 \mathrm{~d}$ & $39.32 \pm 17.57(2)$ & $1.40 \pm 1.73(2)$ & 0.2 & $9.34 \pm 8.99$ \\
\hline & & $21 \mathrm{~d}$ & $17.38(1)$ & $3.18(1)$ & 2.0 & $10.45 \pm 9.40$ \\
\hline
\end{tabular}

${ }^{a} W$, gypsum wallboard; ${ }^{b} S D$, standard deviation; ${ }^{c} n$, number of chambers with same strain, tested during same incubation period; ${ }^{d} N D$, not determined; ${ }^{e} B D L$, below detection limit.

The highest concentration of anisole detected on wallboard was $105 \pm 38 \mu \mathrm{g} / \mathrm{m}^{3}$ and on ceiling tile $46 \pm 1 \mu \mathrm{g} / \mathrm{m}^{3}$. After two weeks of incubation, anisole concentration decreased and remained at detectable concentrations throughout the incubation period. The CFU and mycotoxin data clearly demonstrate that our experimental set-up supported spore production and mycotoxin synthesis (Tables 1 and 2). Previously, we reported similar results for anisole emissions using SDA and gypsum wallboard as growth substrates for S. chartarum [26]. Our results are in agreement with those reported by Wilkins et al. [42], $\mathrm{Li}$ [43] and Mason et al. [37]. All these studies reported anisole emissions as $S$. chartarum grew on gypsum wallboard $[37,42,43]$ and cellulose insulation [43]. These studies also showed that anisole emissions are biogenic and are not commonly associated with general VOCs emitted from building materials. The aforementioned studies included Aspergillus versicolor and other indoor biocontaminants; anisole emissions were not detected among the MVOCs identified for all the molds tested on wallboard or any other building 
Table 2 Growth, MVOC emissions and mycotoxin production by Stachybotrys chartarum growing on ceiling tile

\begin{tabular}{|c|c|c|c|c|c|c|}
\hline $\begin{array}{l}\text { Stachybotrys } \\
\text { chartarum strain }\end{array}$ & Substrate $^{a}$ & $\begin{array}{l}\text { Incubation } \\
\text { period } \\
\text { (Days) }\end{array}$ & $\begin{array}{c}\text { Anisole } \\
\text { concentration } \\
\left(\mu \mathrm{g} / \mathrm{m}^{3}\right) \\
\text { Mean } \pm \mathrm{SD}^{\mathrm{b}}(\mathrm{n})^{\mathrm{c}}\end{array}$ & $\begin{array}{c}\text { 3-octanone } \\
\text { concentration } \\
\left(\mu \mathrm{g} / \mathrm{m}^{3}\right) \\
\text { Mean } \pm \mathrm{SD}(\mathrm{n})\end{array}$ & $\begin{array}{c}\text { Mycotoxin } \\
\text { concentration } \\
\text { (ppb) }\end{array}$ & $\begin{array}{l}\text { CFU } \log _{10} \\
\text { Mean } \pm \text { SD }\end{array}$ \\
\hline \multirow[t]{4}{*}{ ATCC 201210} & C & Start & $0.15(2)$ & $\mathrm{BDL}^{\mathrm{e}}$ & $N D^{d}$ & ND \\
\hline & & $7 d$ & $12.91 \pm 3.29(2)$ & $\mathrm{BDL}$ & ND & ND \\
\hline & & $14 \mathrm{~d}$ & $6.51 \pm 0.26(2)$ & $\mathrm{BDL}$ & ND & ND \\
\hline & & $21 \mathrm{~d}$ & $3.86 \pm 0.05(2)$ & $\mathrm{BDL}$ & ND & ND \\
\hline \multirow[t]{4}{*}{ ATCC 62762} & C & Start & $1.45 \pm 0.35(2)$ & $2.77 \pm 0.45(2)$ & $<0.2$ & TFTC \\
\hline & & $7 d$ & $13.97 \pm 2.50$ & $8.68 \pm 0.42(2)$ & 18 & $8.07 \pm 7.55$ \\
\hline & & $14 \mathrm{~d}$ & $5.94 \pm 0.47(2)$ & $2.02 \pm 0.59(2)$ & 18 & $8.07 \pm 7.55$ \\
\hline & & $21 \mathrm{~d}$ & $7.33 \pm 0.21(2)$ & $1.49 \pm 0.36(2)$ & $>18$ & $8.95 \pm 8.74$ \\
\hline \multirow[t]{5}{*}{ ATCC 34916} & C & Start & $0.28 \pm 0.01(2)$ & $0.40 \pm 0.09$ & $<0.2$ & TFTC \\
\hline & & $7 d$ & $46.41 \pm 1.25(2)$ & $1.32 \pm 0.41$ & $>18$ & $9.9 \pm 9.19$ \\
\hline & & $14 d$ & $5.78 \pm 0.53(2)$ & $1.42 \pm 0.06(2)$ & $>18$ & $9.54 \pm 9.05$ \\
\hline & & $21 d$ & $3.09 \pm 0.37(2)$ & $1.73 \pm 0.66(2)$ & $>18$ & $9.66 \pm 9.22$ \\
\hline & & $28 d$ & $2.08 \pm 0.14(2)$ & $3.56 \pm 0.10(2)$ & 18 & $8.02 \pm 8.00$ \\
\hline \multirow[t]{5}{*}{ ATCC 46994} & C & Start & $2.28 \pm 0.02(2)$ & $1.57 \pm 0.55$ & $<0.2$ & $5.76 \pm 5.91$ \\
\hline & & $7 d$ & $11.64(1)$ & $1.69(1)$ & 2.0 & $9.67 \pm 9.11$ \\
\hline & & $14 d$ & $3.98 \pm 0.08(2)$ & $2.64 \pm 0.56(2)$ & $0.2<x<2.0$ & $9.67 \pm 9.26$ \\
\hline & & $21 d$ & $2.6 \pm 0.2(2)$ & $15.76 \pm 0.52(2)$ & $0.2<x<2.0$ & $9.98 \pm 9.52$ \\
\hline & & $28 d$ & $1.87 \pm 0.16(2)$ & $42.18 \pm 0.97(2)$ & 2.0 & $10.07 \pm 9.38$ \\
\hline \multirow[t]{4}{*}{ RTI 3559} & C & Start & $0.22 \pm 0.08$ & $\mathrm{BDL}$ & ND & ND \\
\hline & & $7 d$ & $13.12 \pm 0.44(2)$ & $3.56 \pm 0.96(2)$ & ND & ND \\
\hline & & $14 \mathrm{~d}$ & $4.13 \pm 0.33(2)$ & $\mathrm{BDL}$ & ND & ND \\
\hline & & $21 \mathrm{~d}$ & $1.95 \pm 0.21(2)$ & $\mathrm{BDL}$ & ND & ND \\
\hline \multirow[t]{4}{*}{ RTI 5802} & C & Start & $0.23 \pm 0.05$ & $3.27 \pm 1.22(2)$ & $<0.2$ & TFTC \\
\hline & & $7 d$ & $13.10 \pm 3.05$ & $10.07 \pm 0.93$ & 2.0 & $9.06 \pm 8.77$ \\
\hline & & $14 \mathrm{~d}$ & $4.19 \pm 0.58(2)$ & $3.72 \pm 0.64$ (2) & $0.2<x<2.0$ & $9.06 \pm 8.77$ \\
\hline & & $21 d$ & $7.48 \pm 0.75$ & $3.53 \pm 0.70(2)$ & 2.0 & $9.53 \pm 9.16$ \\
\hline
\end{tabular}

${ }^{a} \mathrm{C}$, ceiling tile; ${ }^{b} \mathrm{SD}$, standard deviation; ${ }^{c} \mathrm{n}$, number of chambers with same strain, tested during same incubation period; ${ }^{\mathrm{d}} \mathrm{ND}$, not determined; ${ }^{\mathrm{B} D L}$, below detection limit.

materials. Anisole has been proposed as a unique MVOC for S. chartarum [37]. However, in other studies, anisole emissions have been reported for Aspergillus versicolor $[38,41,44]$. As previously mentioned, these are instances that show the complexity of analyzing MVOC profiles due to the diversity of the environmental conditions, mold genera and substrate availability [34]. Our study showed that anisole emissions of $S$. chartarum are detectable within one week of incubation when growing on cellulose-containing building materials. We were able to demonstrate the reproducibility of anisole emissions for a total of nine S. chartarum strains (two from a previous study and seven new ones from the present study) during the first week of growth and the steady-state concentration maintained throughout the incubation period [26]. Robust MVOCs profiles with target compounds such as anisole might increase the sensitivity of a biosensor technology for the identification of S. chartarum in hidden cavities and spaces.

The other MVOCs frequently emitted by most of the S. chartarum strains tested was 3-octanone. The highest concentration on W was $4 \pm 0.7 \mu \mathrm{g} / \mathrm{m}^{3}$ and on $C$ was $42 \pm$ $1 \mu \mathrm{g} / \mathrm{m}^{3}$. Emission patterns of this ketone were variable for both substrates. In ceiling tiles, the concentrations for several strains were below the detection limit. Previous studies reported 3-octanone as an MVOC derived from the degradation of fatty acids [25,42,45]. Several indoor fungi such as Penicillium brevicompactum, Aspergillus versicolor, Eurotium amstelodami and Chaetomium globosum among others emit this ketone as they actively grow on suitable building materials [46].

Gao et al. [36] studied the MVOC emissions of three toxigenic strains of $S$. chartarum when grown on rice and 


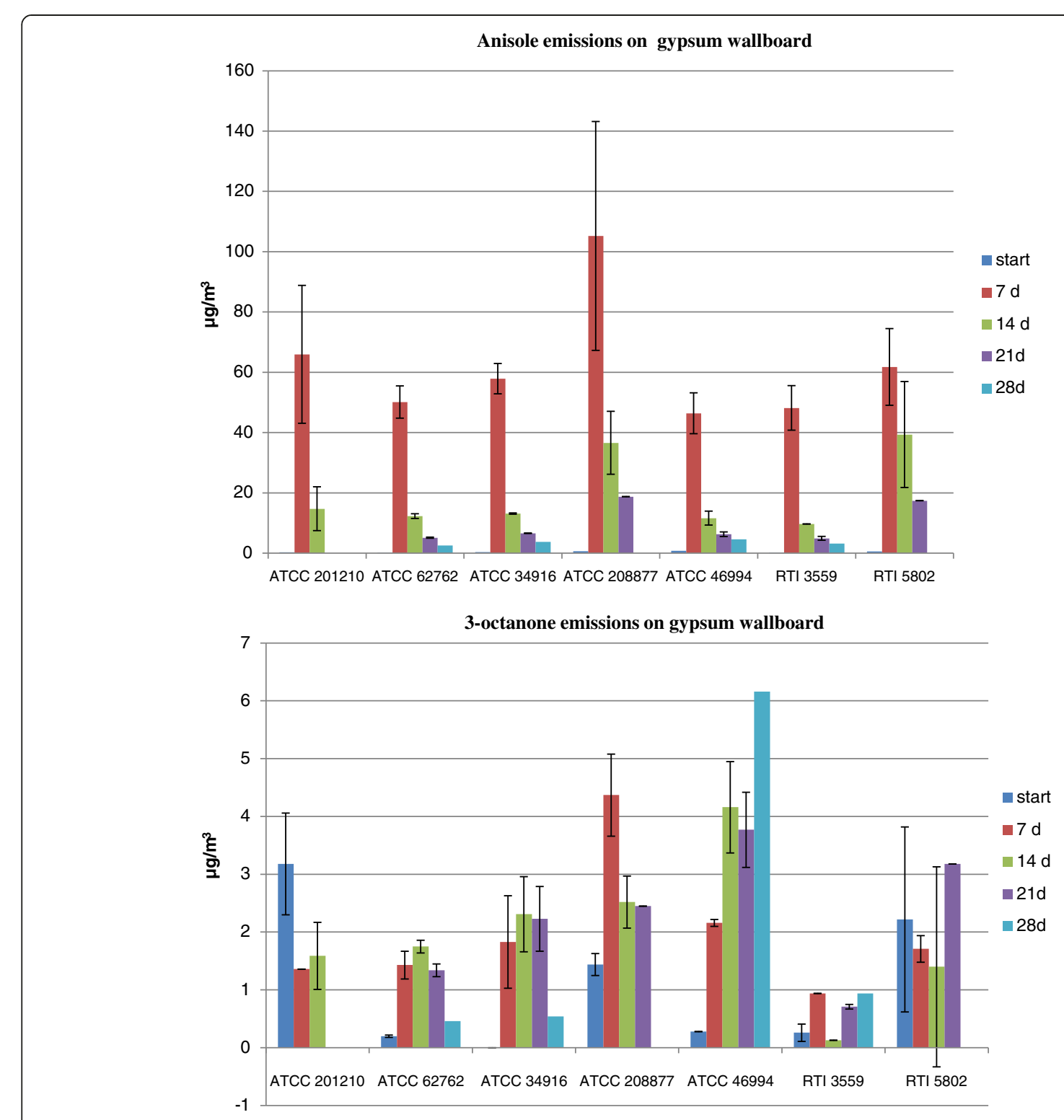

Figure 2 Anisole and 3-octanone emissions on gypsum wallboard. Anisole and 3-octanone emission was followed, as a function of time, during the growth of the different strains of S. chartarum on gypsum wallboard. The bar graph shows the mean \pm SD of anisole and 3-octanone emissions.

gypsum wallboard. We detected two MVOCs similar to those reported by Gao when $S$. chartarum was grown on W; these were: 2-(1-cyclopent-1-enyl-1-methylethyl) cyclopentanone and $\beta$-bisabolene. However, anisole and 3octanone were not detected among the unique MVOCs reported by Gao et al. [36].

Mycotoxin assays showed that all the S. chartarum strains used in our investigation were toxigenic (Tables 1 and 2). Mycotoxin concentrations were variable among all the strains tested and were detected after seven days of incubation. Future studies will include HPLC analysis to identify the mycotoxins synthesized and molecular characterization of mycotoxins' biosynthetic genes and sporulation genes to identify the possible association between anisole and other MVOC emissions and these cellular processes. Several studies suggested that high MVOC production might be associated with spore production and mycotoxin biosynthesis $[20,47]$.

In the food industry, MVOCs have long been used as spoilage predictors for food and grains [48,49]. Karlshøj et al. [50] showed that certain types of MVOCs are emitted during mycotoxins biosynthesis. Therefore, recent trends are aimed at the development of electronic noses (e-noses) as indirect indicators of toxigenic fungi in food [50]. In indoor environments, the use of e-noses for the early detection of mold is a very promising technology. However, the interference of volatiles originating from building materials and the low concentrations of MVOCs are factors that 


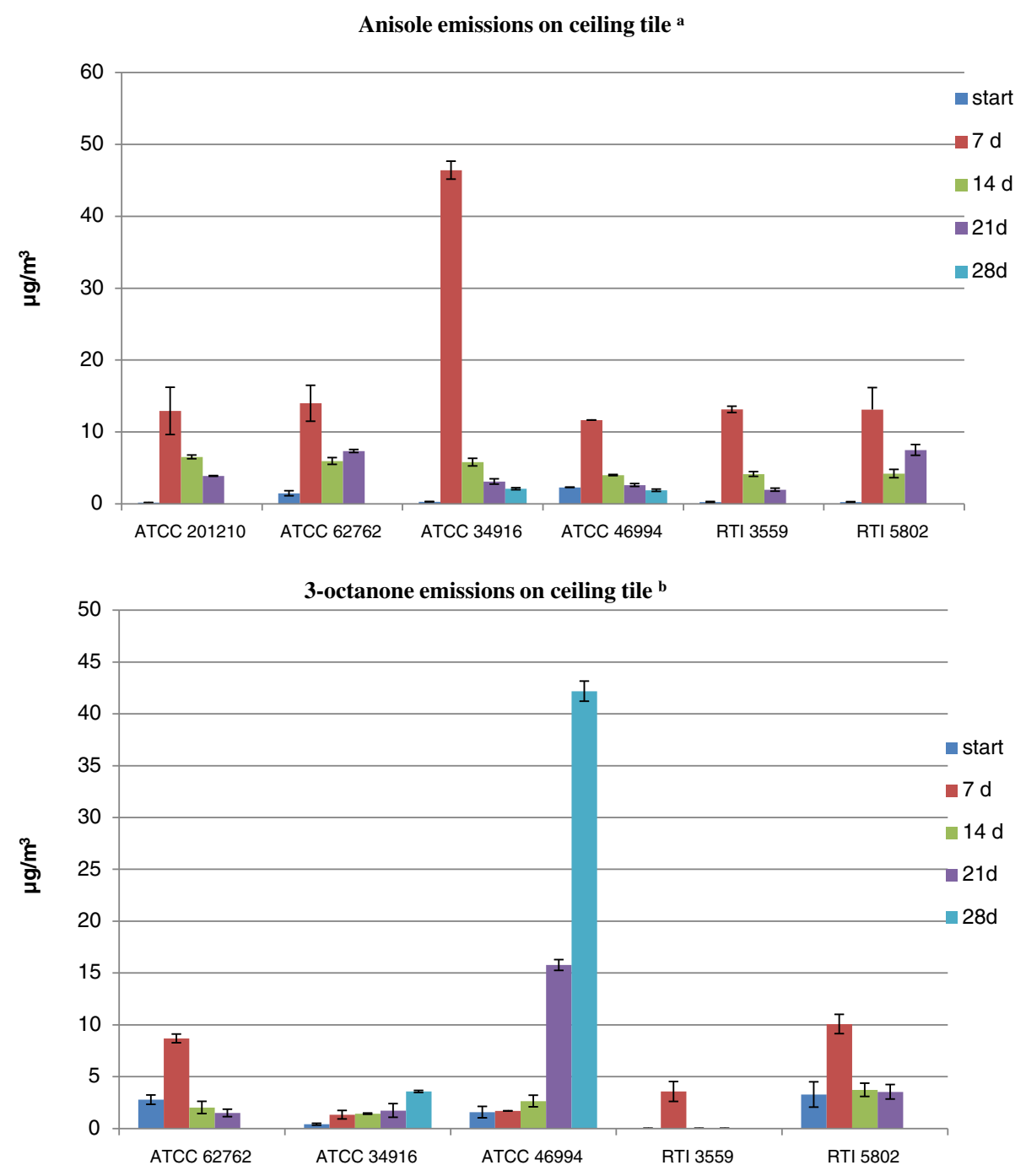

Figure 3 Anisole and 3-octanone emissions on ceiling tile. The bar graph shows the mean \pm SD of anisole and 3-octanone emissions for six independent SC strains growing on ceiling tile. ${ }^{\text {a. }}$ S. chartarum ATCC 208877 MVOCs emissions not tested on ceiling tile; ${ }^{\text {b. }}$ 3-octanone emissions for S. chartarum ATCC 201210 below detection limit.

need to be considered for the development of efficient sensors [51]. Schiffman et al. constructed an e-nose with a potential to effectively discriminate between several fungi species; and demonstrated that sensitive sensors are capable of discriminating specific volatiles [52]. We believe that the construction of a robust Stachybotrys chartarum MVOC library is the first step needed towards the development of an e-nose for the early detection of this mold in indoor environments. In this study (Additional file 1: Table S1), we provided the profiles of MVOCs from seven toxigenic strains of $S$. chartarum (in addition to the two strains we previously reported [26]) when grown on building materials that support mold growth under favorable conditions, and identified anisole (methoxybenzene) as a potential fingerprint for the early detection of this mold (Tables 1 and 2, and Figures 2 and 3). Indeed, the development of an e-nose for S. chartarum promises a major breakthrough for its e early detection in damaged indoor environments. Future studies will need to include the characterization and identification of the mycotoxins produced by $S$. chartarum in order to determine the correlation between toxigenic mycotoxin biosynthesis and MVOC emissions.

\section{Conclusions}

Comparisons of MVOC emissions profiles of seven toxigenic strains of $S$. chartarum growing on gypsum wallboard and ceiling tile show that the ether (anisole) might be an excellent indicator for the growth and the presence of this mold in indoor environments. Robust MVOCs profiles with target compounds such as anisole might increase the sensitivity of a biosensor technology for the identification of $S$. chartarum in hidden cavities and spaces. 


\section{Additional file}

Additional file 1: Table S1. MVOC emissions of Stachybotrys chartarum growing on gypsum wallboard and ceiling tile.

\section{Competing interests}

The authors declare that they have no competing interests.

\section{Authors' contributions}

Conceived and designed the experimental protocols and performed static chambers tests: DAB, SAM. Coordinated the study, analyzed data, and wrote the manuscript: DAB. Performed all the GC-MS analysis: KK. Performed static chamber tests, mycotoxin assays and CFU: SMM. All authors read and approved the final manuscript.

\section{Acknowledgements}

Dr. Victor de Jesus developed the experimental setup used in this research as part of his post-doctoral work (2000-2001) at the US Environmental Protection Agency, Office of Research and Development, National Risk Management Research Laboratory, Air Pollution Prevention Control Division, Durham, NC.

Received: 29 July 2013 Accepted: 28 November 2013

Published: 5 December 2013

\section{References}

1. Andersen B, Frisvad JC, Søndergaard I, Rasmussen IS, Larsen LS: Associations between fungal species and water-damaged building materials. App/ Environ Microbiol 2011, 77(12):4180-4188.

2. Gravesen $\mathrm{S}$, Nielsen PA, Iversen R, Nielsen KF: Microfungal contamination of damp buildings-examples of risk constructions and risk materials. Environ Health Perspect 1999, 107(Suppl 3):505-508.

3. Jarvis BB: Stachybotrys chartarum: a fungus for our time. Phytochemistry 2003, 64(1):53-60.

4. Kuhn DM, Ghannoum MA: Indoor mold, toxigenic fungi, and Stachybotrys chartarum: Infectious disease perspective. Clin Microbiol Rev 2003, 16(1):144-172.

5. Pestka JJ, Yike I, Dearborn DG, Ward MD, Harkema JR: Stachybotrys chartarum, trichothecene mycotoxins, and damp building-related illness: new insights into a public health enigma. Toxicol Sci 2008, 104(1):4-26.

6. Institute of Medicine (IOM): Damp Indoor Spaces and Health. Washington DC: National Academies Press; 2004

7. Dearborn DG, Yike I, Sorenson WG, Miller MJ, Etzel RA: Overview of investigations into pulmonary hemorrhage among infants in Cleveland Ohio. Environ Health Perspect 1999, 107(Suppl 3):495-499.

8. Etzel RA, Montana E, Sorenson WG, Kullman GJ, Allan TM, Dearborn DG: Acute pulmonary hemorrhage in infants associated with exposure to Stachybotrys atra and other fungi. Arch Pediatr Adolesc Med 1998, 152(8):757-762.

9. Johanning E, Biagini R, Hull D, Morey P, Jarvis B, Landsbergis P: Health and immunology study following exposure to toxigenic fungi (Stachybotrys chartarum) in a water-damaged office environment. Int Arch Occup Environ Health 1996, 68(4):207-218.

10. American Industrial Hygiene Association (AlHA): Total (viable and nonviable) fungi and substances derived from fungi in air,bulk, and surface samples. In Field Guide for the Determination of Biological Contaminants in Environmental Samples. Edited by Dillon HK, Heinsohn PA, Miller DM. Fairfax,VA;USA: American Industrial Hygiene Association; 1996:119-130

11. Ammann HM, Hodgson M, Nevalainen A, Prezant B: Indoor mold: basis for health concerns. In Recognition, Evaluation and Control of Indoor Mold. Edited by Prezant B, Weekes DM, Miller JD. Fairfax,VA;USA: American Industrial Hygiene Association; 2008:1-19.

12. Ström G, West J, Wessén B, Palmgren U: Quantitative analysis of microbial volatiles in damp Swedish houses. In Health Implications of Fungi in Indoor Environments. Edited by Samson RA, Flannigan B, Flannigan ME, Verhoeff AP, Adan OCG, Hoekstra ES. Amsterdam: Elsevier; 1994:291-305.

13. Portnoy JM, Barnes CS, Kennedy K: Current reviews of allergy and clinical immunology - Sampling for indoor fungi. J Allergy Clin Immunol 2004, 113(2):189-198.
14. Wessén B, Schoeps K-O: Microbial volatile organic compounds What substances can be found in sick buildings? Analyst 1996, 121(9):1203-1205

15. Wessén B, Ström G, Schoeps K-O: MVOC profiles - a tool for indoor -air quality assessment. In Morawska L, Bofinger ND, Maroni M. Oxford, United Kingdom: Elsevier Science Ltd; 1995:67-70.

16. Korpi A, Jarnberg J, Pasanen AL: Microbial volatile organic compounds. Crit Rev Toxicol 2009, 39(2):139-193.

17. Korpi A, Kasanen JP, Alarie Y, Kosma VM, Pasanen AL: Sensory irritating potency of some microbial volatile organic compounds (MVOCs) and a mixture of five MVOCs. Arch Environ Health 1999, 54(5):347-352.

18. Kreja L, Seidel HJ: Evaluation of the genotoxic potential of some microbial volatile organic compounds (MVOC) with the comet assay, the micronucleus assay and the HPRT gene mutation assay. Mutat Res 2002, 513(1-2):143-150.

19. Kreja L, Seidel $\mathrm{H}$-J: On the cytotoxicity of some microbial volatile organic compounds as studied in the human cell line A 549. Chemosphere 2002, 49:105-110

20. Ammann HM: Microbial Volatile Organic Compounds. In Bioaerosols: Assessment and Control. Edited by Macher J. Cincinnati, OH: ACGIH; 1999:1-17.

21. Hachem C, Chaubey Y, Fazio P, Rao J, Bartlett K: Statistical analysis of microbial volatile organic compounds in an experimental project: identification and transport analysis. Indoor Built Environ 2010, 19(2):275-285.

22. Morey P, Worthan A, Weber A, Horner E, Black M, Muller W: Microbial VOCs in moisture damaged buildings. In IAQ Proceedings of Healthy Buildings. Edited by Wood JE, Grimsrud DT, Boschi N. Bethesda, MD: ISIAQ; 1997:245-250.

23. Fischer G, Schwalbe R, Moller M, Ostrowski R, Dott W: Species-specific production of microbial volatile organic compounds (MVOC) by airborne fungi from a compost facility. Chemosphere 1999, 39(5):795-810.

24. Wilkins K, Larsen K: Variation of volatile organic compound patterns of mold species from damp buildings. Chemosphere 1995, 31(5):3225-3236.

25. Larsen TO, Frisvad JC: Characterization of volatile metabolites from 47 Penicillium taxa. Mycol Res 1995, 99:1153-1166.

26. Betancourt DA, Dean TR, Menetrez MY, Moore SA: Characterization of microbial volatile organic compounds (MVOC) emitted by Stachybotrys chartarum. In Proceedings for the AWMAVEPA Indoor Environmental Quality: Problems, Research and Solutions Conference, Research Triangle Park, NC; 2006. Online http://www.awma.org.

27. Crow SA, Ahearn DG, Noble JA, Moyenuddin M, Price DL: Microbial ecology of buildings: effects of fungi on indoor air quality. Am Environ Lab 1994, 2:16-18

28. Dean TR, Betancourt D, Menetrez MY: A rapid DNA extraction method for PCR identification of fungal indoor air contaminants. J Microbiol Meth 2004, 56(3):431-434.

29. Menetrez MY, Foarde KK, Webber TD, Betancourt D, Dean T: Growth response of Stachybotrys chartarum to moisture variation on common building materials. Indoor Built Environ 2004, 13:183-187.

30. ASTM D 6329-98: Standard guide for developing methodology for evaluating the ability of indoor materials to support microbial growth using static environmental chambers. West Conshohocken, PA: American Society for Testing and Materials (ASTM); 1998.

31. Betancourt DA, Dean TR, Menetrez MY: Method for evaluating mold growth on ceiling tile. J Microbio/ Meth 2005, 61(3):343-347.

32. Brasel TL, Douglas DR, Wilson SC, Straus DC: Detection of airborne Stachybotrys chartarum macrocyclic trichothecene mycotoxins on particulates smaller than conidia. Appl Environ Microbiol 2005, 71(1):114-122.

33. Vesper SJ, McKinstry C, Haugland RA, lossifova Y, Lemasters G, Levin L, Khurana Hershey GK, Villareal M, Bernstein DI, Lockey J, et al: Relative moldiness index as predictor of childhood respiratory illness. J Expo Sci Environ Epidemiol 2007, 17(1):88-94.

34. Claeson A-S, Levin J-O, Blomquist G, Sunesson A-L: Volatile metabolites from microorganisms grown on humid building materials and synthetic media. J Environ Monit 2002, 4(5):667-672

35. Claeson A-S, Sandström M, Sunesson A-L: Volatile organic compounds (VOCs) emitted from materials collected from buildings affected by microorganisms. J Environ Monit 2007, 9(3):240-245.

36. Gao P, Martin J: Volatile metabolites produced by three strains of Stachybotrys chartarum cultivated on rice and gypsum board. Appl Occup Environ Hyg 2002, 17(6):430-436.

37. Mason S, Cortes D, Horner WE: Detection of Gaseous Effluents and ByProducts of Fungal Growth that Affect Environments (RP-1243). HVAC\&R Res 2010, 16(2):109-121. 
38. Moularat S, Robine E, Ramalho O, Oturan MA: Detection of fungal development in closed spaces through the determination of specific chemical targets. Chemosphere 2008, 72(2):224-232.

39. Wilkins K, Nielsen KF, Din SU: Patterns of volatile metabolites and nonvolatile trichothecenes - produced by isolates of Stachybotrys, Fusarium, Trichoderma, Trichothecium and Memnoniella. Environ Sci Pollut R 2003, 10(3):162-166.

40. Menetrez MY, Foarde KK: Microbial volatile organic compound emission rates and exposure model. Indoor Built Environ 2002, 11(4):208-213.

41. Sunesson A-L, Vaes WHJ, Nilsson C-A, Blomquist G, Anderson B, Carlson R: Identification of volatile metabolites from five fungal species cultivated on two media. Appl Environ Microbiol 1995, 61(8):2911-2918.

42. Wilkins K, Larsen K, Simkus M: Volatile metabolites from mold growth on building materials and synthetic media. Chemosphere 2000, 41(3):437-446.

43. Li R: Mould growth on building materials and the effects of borate-based preservatives, MS Thesis. University of British Columbia; 2005.

44. Schuchardt S, Kruse H: Quantitative volatile metabolite profiling of common indoor fungi: relevancy for indoor air analysis. $J$ Basic Microbiol 2009, 49(4):350-362

45. Wurzenberger M, Grosch W: Stereochemistry of the cleavage of the 10- hydroperoxide isomer of linoleic acid to 1-octen-3-ol by a hydroperoxide lyase from mushrooms (Psalliota bispora). Biochim Biophys Acta 1984, 795(1):163-165.

46. Schleibinger $\mathrm{H}$, Laussmann D, Brattig C, Mangler M, Eis D, Ruden $\mathrm{H}$ : Emission patterns and emission rates of MVOC and the possibility for predicting hidden mold damage? Indoor Air 2005, 15(Suppl 9):98-104.

47. Zeringue $\mathrm{HJ}$, Bhatnagar D, Cleveland TE: $\mathrm{C}_{15} \mathrm{H}_{24}$ volatile compounds unique to aflatoxigenic strains of Aspergillus flavus. Appl Environ Microbiol 1993, 59(7):2264-2270.

48. Karlshoj K, Nielsen PV, Larsen TO: Fungal volatiles: biomarkers of good and bad food quality. In Food Mycology. Edited by Samson RA, Dijksterhus J. Boca Raton, FL: CRC Press; 2007:279-302.

49. Magan N, Evans P: Volatiles as an indicator of fungal activity and differentiation between species, and the potential use of electronic nose technology for early detection of grain spoilage. J Stored Prod Res 2000, 36(4):319-340

50. Karlshøj K, Nielsen PV, Larsen TO: Differentiation of closely related fungi by electronic nose analysis. J Food Sci 2007, 72(6):M187-M192.

51. Kuske M, Romain AC, Nicolas J: Microbial volatile organic compounds as indicators of fungi. Can an electronic nose detect fungi in indoor environments? Build Environ 2005, 40(6):824-831.

52. Schiffman SS, Wyrick DW, Gutierrez-Osuna R, Nagle HT: Effectiveness of an electronic nose for monitoring bacterial and fungal growth. In Proceedings of the $7^{\text {th }}$ International Symposium on Olfaction and Electronic Noses. Edited by Gardner JW, Persaud KC. Brighton, UK: Taylor and Francis; 2000:173-180

doi:10.1186/1471-2180-13-283

Cite this article as: Betancourt et al:: Microbial volatile organic compound emissions from Stachybotrys chartarum growing on gypsum wallboard and ceiling tile. BMC Microbiology 2013 13:283.

\section{Submit your next manuscript to BioMed Central and take full advantage of:}

- Convenient online submission

- Thorough peer review

- No space constraints or color figure charges

- Immediate publication on acceptance

- Inclusion in PubMed, CAS, Scopus and Google Scholar

- Research which is freely available for redistribution

Submit your manuscript at www.biomedcentral.com/submit
Biomed Central 